\title{
Evaluation of antioxidant activity
} and total phenol content of Gracilaria bursa-pastoris harvested in Nador lagoon for an enhanced economic valorization

\author{
Mohamed Ramdani ${ }^{1 \dagger}$, Ouahid Elasri ${ }^{2 *}{ }^{*}$, Nezha Saidi $^{3}$, Najat Elkhiati ${ }^{4}$, Fouzi A. Taybi ${ }^{1}$, Mohammed Mostareh ${ }^{1}$, \\ Oulya Zaraali ${ }^{5}$, Benyounes Haloui ${ }^{1}$ and Mohammed Ramdani ${ }^{3}$
}

\begin{abstract}
Background: The Gracilaria bursa-pastoris is an abundant alga that is responsible for the eutrophication in Nador lagoon in Morocco. Therefore, the lagoon is a deposit of bioresources whose economic value can be enhanced. Antioxidative properties of seaweed extracts have been studied in several geographic regions, but only a few studies have been performed on tropical seaweed species, and no research has been done to determine antioxidant activity and valorization of the indigenous algae in Nador lagoon in Morocco.

Methods: The present study evaluated the antioxidant potential of methanolic and aqueous extracts from Gracilaria bursa-pastoris by measuring the 2,2-diphenyl-1-picrylhydrazyl (DPPH) radical scavenging activity and total content of phenolic, flavonoids and flavonols content in each extract.

Results: This study showed that this macroalgae contained a high total phenolic content (142.26 and 79.43 mg GAE g-1 extract) for ethanolic and aqueous extracts, respectively. All extracts exhibited a DPPH radical scavenging activity, and the methanolic extracts demonstrated a great antioxidant potential with very low value of EC50 $(0.085 \mathrm{mg} / \mathrm{mL})$, significantly equivalent to $\mathrm{EC} 50(0,028 \mathrm{mg} / \mathrm{mL})$ of commercial antioxidant ascorbic acid. These results suggest that the macroalgae have a great antioxidant potential which could be considered for future applications in medicine, food production or cosmetic industry in Morocco.

Conclusions: This work showed that the ethanolic extract was rich in phenolic compounds. This extract exhibited the highest antioxidant activity which may be explained by the presence of a large quantity of phenolic compounds. The Gracilaria bursa-pastoris can be utilized as a source of natural antioxidant compounds.
\end{abstract}

Keywords: Antioxidant activity, Macroalgae, Gracilaria bursa-pastoris, DPPH

\section{Background}

Since the year 2000, the seaweeds have attracted attention in the search for bioactive compounds to develop new drugs and healthy foods $[1,2]$. In particular, these organic resources are a very important and commercially

\footnotetext{
*Correspondence: elasriouahid@yahoo.fr

${ }^{\dagger}$ Mohamed Ramdani and Ouahid Elasri contributed equally to this work

2 Biochemistry and Biotechnology Laboratory, Mohamed First University, Oujda, Morocco

Full list of author information is available at the end of the article
}

valuable resource for food, fodder, soil conditioners, pharmaceuticals, and production of green energy [3, 4]. Marine macroalgae are a valuable food resource which contains low calories, and they are rich in vitamins, minerals, proteins, polysaccharides, steroids, and dietary fibers [5-7]. In 2004, Ahn et al. has confirmed the presence of bioactive compounds such as vitamins, minerals, dietary fiber, and polysaccharides in some seaweeds.

On the other side, some authors have found other special bioactive compounds such as alkaloids, terpenes, 
bromophenols, phlorotannins, ascorbic acid, tocopherols, and carotenoids, in algae which have antioxidant potential [8-13]. These observations suggest that these bioactive compounds can have strong antioxidant properties.

The search for natural antioxidant compounds has gained considerable attention and the number of publications on antioxidants and oxidative stress has nearly quadrupled [14]. Because the antioxidant compounds play an important role against various diseases (Chronic inflammation, atherosclerosis, cancer, and cardiovascular disorders) and aging biochemical processes, this explains their considerable commercial potential in medicine, food production, and the cosmetic industry [15, 16]. Currently, the utilization of antioxidants from natural sources is accentuated because the consumers prefer natural products and they are afraid about the potential toxic effects of synthetic antioxidants [17]. Most countries have limited the use of synthetic antioxidant compounds in the food products because of their side effects [18]. Thus, it is essential to develop and utilize effective natural antioxidant molecules.

The Nador lagoon, also called Marchica lagoon, is the only lagoon ecosystem in the Moroccan coast facing the Mediterranean Sea . It covers an area of $115 \mathrm{~km}^{2}$ with water depths from 3 to $8 \mathrm{~m}$. [19, 20]. The daily discharges of domestic, agricultural, and industrial waste into the lagoon stimulate the proliferation of algae called "harmful algal blooms" [21]. Gracilaria bursa-pastoris is an abundant alga that is responsible for the eutrophication in this lagoon [3]. The choice of this alga (Gracilaria bursa-pastoris) was based on its potential source for the extraction of new natural medicines, its important role for industrial and biotechnological applications due to its content of phycocolloids, the main source of agar $\alpha-(1,4)-3,6$-anhydro- $\mathrm{L}$-galactose and $\beta-(1,3)$-D-galactose with little esterification in cell wall, the content of bioactive metabolites like the primary compound with antibiotic activity acrylic acid [22]. Therefore, the lagoon is a deposit of bioresources whose economic value can be enhanced.

Antioxidative properties of seaweed extracts have been studied in several geographic regions, but only a few studies have been performed on tropical seaweed species and no research has been done to determine antioxidant activity and valorization of the indigenous algae in Nador lagoon in Morocco [23-26].

Faced with the challenge to valorize this natural wonder, it is necessary that total phenolic content, total antioxidant capacity (in soluble of lipid and water), total protein, total carbohydrate, and vitamin (A, C, and E) contents were determined in Gracilaria bursa-pastoris, in order to identify the new resources of natural antioxidant molecules. The present study evaluated the antioxidant potential of methanolic and aqueous extracts from Gracilaria bursa-pastoris from Nador lagoon in Mediterranean Moroccan costs by measuring the 2,2-diphenyl-1- picrylhydrazyl (DPPH) radical-scavenging activity and total content of phenolic, flavonoids, and flavonols content in each extract.

\section{Methods}

\section{Drugs and chemicals}

1,1-Diphenyl-2-picrylhydrazyl $\left(\mathrm{DPPH}^{*}\right)$, potassium ferricyanide $\left(\mathrm{K}_{3} \mathrm{Fe}_{3}+(\mathrm{CN}) 6\right)$, trichloroacetic acid (TCA), ferric chloride $\left(\mathrm{FeCl}_{3}\right), \beta$-carotene, linoleic acid, Tween40, Folin-Ciocalteu's reagent, ammonia solution $\left(\mathrm{NH}_{3}\right)$, sulfuric acid $\left(\mathrm{H}_{2} \mathrm{SO}_{4}\right)$, hydrochloric acid $(\mathrm{HCl})$, picric acid, acetic anhydride, chloroform, Fehling's solutions $\mathrm{A}$ and $\mathrm{B}$, sodium carbonate, Aluminum chloride $\left(\mathrm{AlCl}_{3}\right)$ and bovine blood, ethanol, methanol, acetone, and hexane were obtained from Merck (Darmstadt, Germany). Gallic acid, Quercetin, Tannic acid, Butylated hydroxyanisole (BHA), and Butylated hydroxytoluene (BHT) are used as positive standards. Authentic standards were purchased from Sigma-Aldrich, Fluka, and Merck. All other chemicals used were of analytical grade.

\section{Collection and preparation of algal extracts}

Red algae Gracilaria bursa-pastoris was collected from Nador lagoon in May 2015 (Fig. 1). The algal species was identified by Professor N. Elkhiati. In the laboratory, the algae was carefully cleaned, washed several times with tap water, distilled water, then dried by oven at $40{ }^{\circ} \mathrm{C}$, ground, and kept in dark (Fig. 2). Macroalgae plant was lyophilized and milled into powder before extraction. Lyophilized samples (10 g) of Gracilaria powder were macerated with $50 \mathrm{~mL}$ of ethanol. The mixture was stirred under ambient temperature for $4 \mathrm{~h}$ or refluxed at $40{ }^{\circ} \mathrm{C}$ for $2 \mathrm{~h}$. After filtration, the solvent was concentrated on a rotary evaporator under reduced pressure at $40{ }^{\circ} \mathrm{C}$. The aqueous extracts were prepared by the same method using distilled water and extracts were concentrated by drying at $40{ }^{\circ} \mathrm{C}$ and stored at $-20{ }^{\circ} \mathrm{C}$. For each extract, different concentrations $(0.02,0.04,0.08,0.16$, and $0.32 \mathrm{mg} / \mathrm{mL}$ ) were prepared from the algae powder and then tested for antioxidant activity.

\section{Phytochemicals compounds \\ Determination of total phenolics contents}

The total phenolic contents were determined by the Folin-Ciocalteu method by following three steps [27]. In the first step, we mixed $6 \mu \mathrm{L}$ of ultrapure and $500 \mu \mathrm{L}$ of Folin-Ciocalteu reagent with $100 \mu \mathrm{L}$ of the dissolved extract. After $1 \mathrm{~min}$, in the second step, we added $1.5 \mathrm{~mL}$ of $\mathrm{Na}_{2} \mathrm{CO}_{3}(20 \%)$ and the volume was adjusted to $10 \mathrm{~mL}$ 


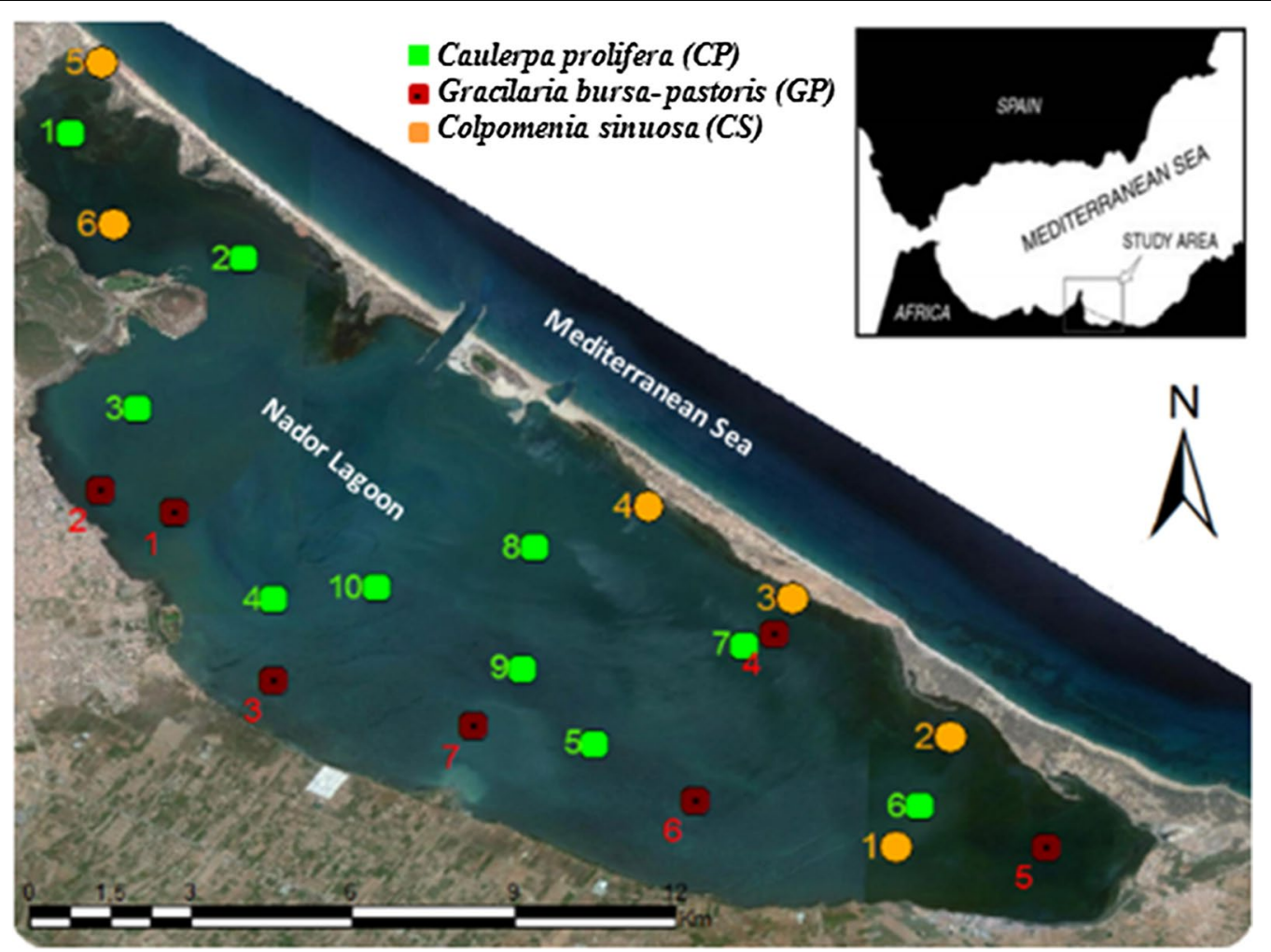

Fig. 1 Map of Nador lagoon indicating the collecting sites in Mediterranean Moroccan costs [3]

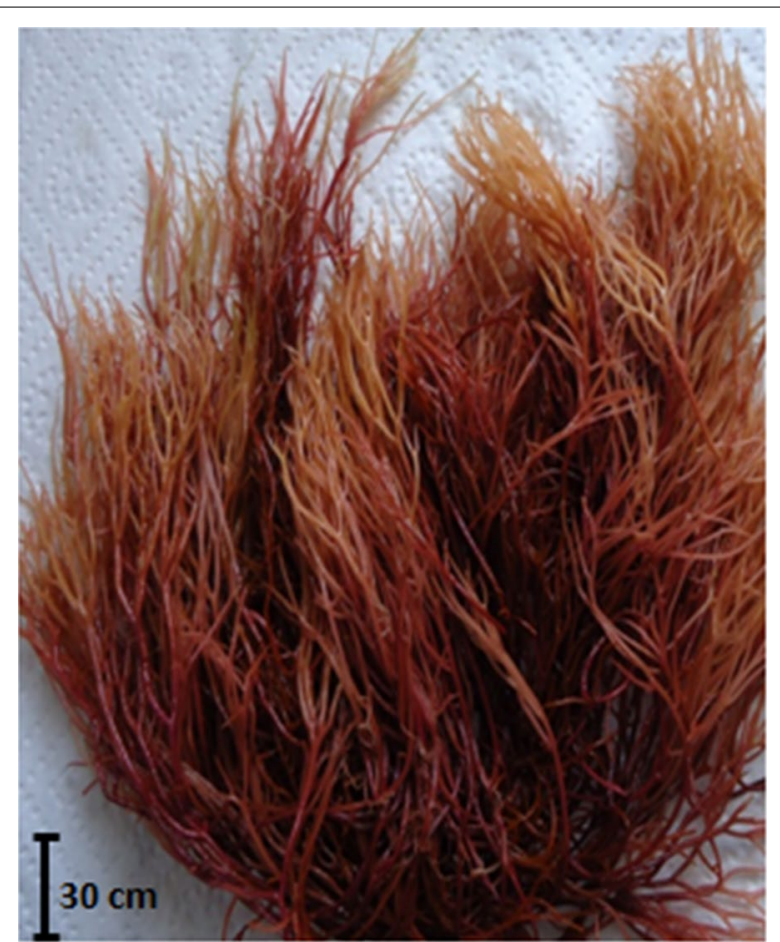

Fig. 2 Gracilaria bursa-pastoris with ultrapure water. In the third step, after $30 \mathrm{~min}$ of incubation at room temperature, we measured the absorbance at $760 \mathrm{~nm}$. Gallic acid was used for the calibration curve. All the results were expressed as Gallic acid equivalents (mg GAE/g dry weight of the extracts) according to the following equation:

$$
Y=0.0053 X-0.0030\left(R^{2}=0.995\right) \text {. }
$$

$Y$ : The absorbance. $X$ : The concentration of gallic acid in $\mathrm{mg} / \mathrm{mL}$.

\section{Determination of total flavonoids contents}

The flavonoids contents were estimated by the $\mathrm{AlCl}_{3}$ method [28]. We mixed $1 \mathrm{~mL}$ of extract solution with $1 \mathrm{~mL}$ of $2 \%$ methanolic $\mathrm{AlCl}_{3}{ }^{*} 6 \mathrm{H}_{2} \mathrm{O}$. After $30 \mathrm{~min}$, we measured the absorbance at $430 \mathrm{~nm}$. Quercetin (0-20 mg/l) prepared in methanol was used as a standard. The amount of flavonoids was expressed as quercetin equivalents (mg RE/g dry weight of the extract) according to the following equation [29]:

$$
Y=0.031 X+0.100\left(R^{2}=0.995\right) \text {. }
$$


$Y$ : the absorbance. $X$ : the concentration of quercetin in $\mathrm{mg} / \mathrm{mL}$.

\section{Free radical-scavenging activity Determination of antioxidant activity}

Aqueous and ethanolic extracts were subjected to screening for their possible antioxidant activities. The antioxidant activity was assessed using 2,2-diphenyl1-picrylhydrazyl (DPPH) radical-scavenging assay and ascorbic acid bleaching test. DPPH can be used to accurately titrate the oxidizable groups of biomolecules [30], and has commonly been used to estimate the antioxidant capacity of complex mixtures including plant oils, many of which contain high concentrations of monoterpenes [31].

\section{Free radical-scavenging activity experimental}

The free radical-scavenging activity of aqueous and ethanolic extracts was measured according to the method of Brand-Williams et al. 1995 using the stable 2, 2-diphenyl1-picrylhydrazyl radical (DPPH). The model of scavenging DPPH radical has been widely used for estimating the free radical-scavenging activities of plant extracts/antioxidants [1]. DPPH radical is a stable-free radical, so the antioxidants are able to reduce DPPH radical to the nonradical form DPPH-H. The DPPH-scavenging activities of antioxidants are attributed to their hydrogen-donating abilities [7] (Fig. 3). The results were expressed in percentage of inhibition of DPPH.

$0.6 \mathrm{~mL}$ of various concentrations of the each extract was used. They are mixed with $2.4 \mathrm{~mL}$ of a $0.004 \%$ methanol solution of DPPH (Sigma-Aldrich). At room temperature, after waiting for $30 \mathrm{~min}$ incubation period, the absorbance was read at $517 \mathrm{~nm}$. Scavenging effect of DPPH radical was calculated using the following equation:

$$
I \%=\left[\left(A_{\text {blank }}-A_{\text {sample }}\right) / A_{\text {blank }}\right] \times 100 .
$$

$A_{\text {sample: }}$ the absorbance of test extract. $A_{\text {blank: }}$ the absorbance of the control reaction.

The IC50 value represents the concentration of the extract required to quench $50 \%$ of DPPH under experimental conditions.

\section{Results and discussion \\ Phytochemicals compounds}

The total phenolic and flavonoid content of the extracts, as estimated by the Folin-Ciocalteu reagent method, were 79.43 and 142.26 (mg GAE/g extract) at $40{ }^{\circ} \mathrm{C}$ and 27.47 and 36.61 (mg Q g ${ }^{-1}$ extract) at $20{ }^{\circ} \mathrm{C}$ for aqueous and ethanolic extracts, respectively. The total flavonol contents were 59.04 and 64.87 (mg Q g ${ }^{-1}$ extract) at $40{ }^{\circ} \mathrm{C}$ and 19.22 and $49.12\left(\mathrm{mg} \mathrm{Q} \mathrm{g}^{-1}\right.$ extract) at $20{ }^{\circ} \mathrm{C}$ (Table 1 ). These results showed that the higher content of total polyphenols was found in the ethanolic extract which constituted the major antioxidant compounds. Also, we notice that total phenolic and flavonol are the major extracts at $40{ }^{\circ} \mathrm{C}$ more than at $20{ }^{\circ} \mathrm{C}$. It demonstrated that heating promotes the extraction of antioxidant phenolic and flavonol compounds. In contrast, flavonoid content is weakly higher at $20{ }^{\circ} \mathrm{C}$. The temperature affects the extraction processes by varying the alga matrix properties, solvent, pressure, and time [32]. In fact, temperature increases mass transfer during extraction by destroying the alga membrane structure, thus enhancing extraction and decreasing extraction time [33].

Yildiz et al. [16] reported a low phenolic content in the Turkey G. bursa-pastoris methanolic extract $(0.35 \mathrm{mg}$

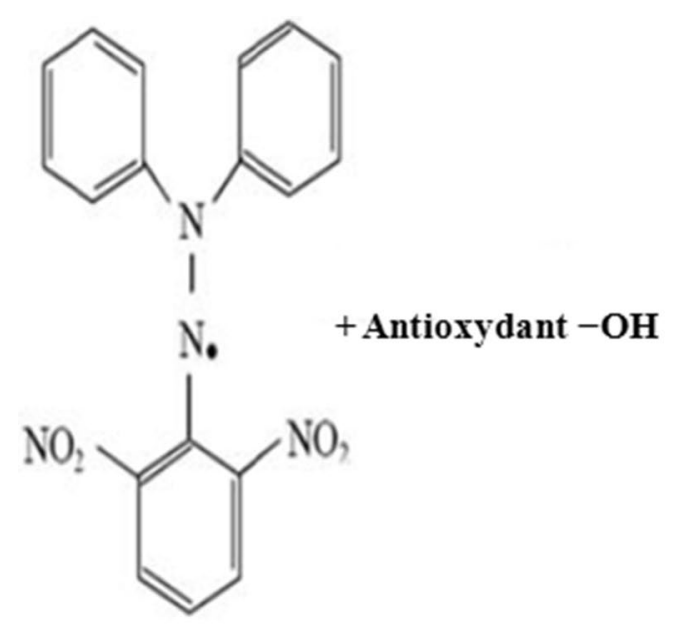

DPPH (Purple)<smiles>CN(c1ccccc1)c1ccccc1</smiles>

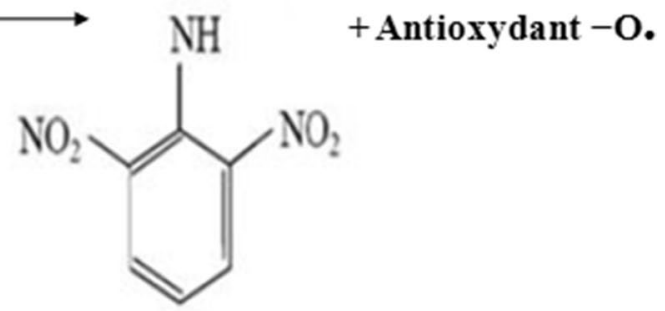

DPPHH (Yellow)

Fig. 3 DPPH-scavenging activities of antioxidants 
Table 1 The total phenolic, flavonoid, and flavonol contents in the G. bursa-pastoris extracts

\begin{tabular}{|c|c|c|c|c|}
\hline Extracts & Heating $\left({ }^{\circ} \mathrm{C}\right)$ & $\begin{array}{l}\text { Total phenolic content } \\
\text { (mg GAE g }{ }^{-1} \text { extract) }\end{array}$ & $\begin{array}{l}\text { Total flavonoid content } \\
\text { (mg Q g } \\
-1 \text { extract) }\end{array}$ & $\begin{array}{l}\text { Total flavonol content } \\
\text { (mg Q g } \\
\text {-1 extract) }\end{array}$ \\
\hline \multirow[t]{2}{*}{ Ethanolic } & 20 & $99.62 \pm 1.2$ & $36.61 \pm 0.3$ & $49.12 \pm 0.7$ \\
\hline & 40 & $142.26 \pm 0.8$ & $32.67 \pm 0.09$ & $64.87 \pm 0.05$ \\
\hline \multirow[t]{2}{*}{ Aqueous } & 20 & $42.2 \pm 0.09$ & $27.47 \pm 0.04$ & $19.22 \pm 0.12$ \\
\hline & 40 & $79.43 \pm 0.58$ & $15.86 \pm 1.53$ & $59.04 \pm 0.09$ \\
\hline
\end{tabular}

Table 2 Antioxidant activity of aqueous and ethanolic extracts determined by DPPH' radical-scavenging assay

\begin{tabular}{|c|c|c|c|c|c|}
\hline \multirow{3}{*}{$\begin{array}{l}\text { Concentration } \\
\mathrm{mg} / \mathrm{mL}\end{array}$} & \multicolumn{5}{|c|}{ Inhibition ratio (\%) } \\
\hline & \multicolumn{2}{|c|}{$\begin{array}{l}\text { Ethanolic } \\
\text { extract }\end{array}$} & \multicolumn{2}{|c|}{$\begin{array}{l}\text { Aqueous } \\
\text { extract }\end{array}$} & \multirow[t]{2}{*}{ Ascorbic acid } \\
\hline & $20^{\circ} \mathrm{C}$ & $40^{\circ} \mathrm{C}$ & $20^{\circ} \mathrm{C}$ & $40^{\circ} \mathrm{C}$ & \\
\hline 0.32 & 74 & 81 & 61 & 69 & 90 \\
\hline 0.16 & 58 & 67 & 40 & 47 & 81 \\
\hline 0.08 & 42 & 48 & 30 & 38 & 73 \\
\hline 0.04 & 31 & 37 & 26 & 27 & 65 \\
\hline 0.02 & 25 & 30 & 18 & 20 & 42 \\
\hline IC50 & 0.096 & 0.085 & 0.176 & 0.167 & 0.028 \\
\hline
\end{tabular}

Gallic acid/g). This difference could be attributed to the origin of the marine algae. Much of literature refers to the plant phenolics compounds' direct antioxidant effect.

\section{DPPH radical-scavenging and antioxidant activities of Gracilaria bursa-pastoris extracts}

Results of free radical-scavenging activity of aqueous and ethanolic extracts are given in Table 2. Data in the table indicated that the radical-scavenging activities of the extracts increased with increasing concentration from 0.02 to $0.32 \mathrm{mg} / \mathrm{mL}$. It is showed a very strong antioxidant activity of G. bursa-pastoris ethanolic extract.

This extract exhibited the highest activity with a very low EC50 $\left(0.085 \mathrm{mg} \mathrm{mL}^{-1}\right)$ significantly equivalent to EC50 of the commercial antioxidants tested, ascorbic acid $\left(0.028 \mathrm{mg} \mathrm{mL}^{-1}\right)$. The antioxidant activity of ethanolic extract was found nearly two times higher than that of aqueous extract. Phenolic compounds are widely distributed in seaweeds and are known to exhibit higher antioxidative activities and chemopreventive agents [34]. According to this result, it is clearly indicated that $G$. bursa-pastoris has a high antioxidant activity. Phenolic compounds in this marine alga are correlated with antioxidant activity and also dependent on the solvent and algal species used for extraction [35].

Basically, increase in total phenolic content may increase antioxidant properties. Phenolic compounds act as electron donors and may neutralize the unwanted reactions created by free radicals in the body. The positive correlation between polyphenolic content of algae and its antioxidant activity is well documented [36]. More recently, Jimenez-Escrig et al. [37] determined that the DPPH-free radical scavenging by brown and red algal extracts were positively correlated with the total polyphenol content of these extracts. Several studies have demonstrated a highly significant correlation between the phenolic content and the antioxidant activity in seaweed extracts, [38-41]. These results suggest that the antioxidant activity of G. bursa-pastoris extracts could be correlated with its high phenolic content.

\section{Conclusion}

This study showed that the ethanolic extract was highly rich in phenolic compounds. This extract exhibited a highest antioxidant activity which may be explained by the presence of a strong quantity of phenolic compounds. The results obtained in this study shows that G. bursapastoris can be utilized as a source of natural antioxidant compounds. Therefore, the G. bursa-pastoris seaweed, due its easily accessible source of natural antioxidant molecules, may become valuable for the development of therapeutic products, food supplement, and pharmaceutical applications.

\section{Authors' contributions}

$\mathrm{MR}, \mathrm{BH}$, and NE designed the experiments; MR, OE, and NS performed the experiments; OE, FT, MM, MR, and OZ wrote this manuscript. All authors read and approved the final manuscript.

\section{Author details}

${ }^{1}$ Ecology, Water and Environment Laboratory, Mohamed First University,

Oujda, Morocco. ${ }^{2}$ Biochemistry and Biotechnology Laboratory, Mohamed First University, Oujda, Morocco. ${ }^{3}$ Applied Analytical Chemistry, Materials and Environment Laboratory, Mohamed First University, Oujda, Morocco. ${ }^{4}$ Department of Biology, Ain Chock Faculty, Casablanca, Morocco. ${ }^{5}$ Applied Biology and Pathology Laboratory, Abdelmalek Essaâdi University, Tetouan, Morocco.

\section{Acknowledgements}

The authors warmly thank Abdelhakim Mesfioui, Director of Nador INRH, and Ahmed Chihani a diver in Nador lagoon for all the necessary materials needed for collecting G. bursa-pastoris macroalgae.

Competing interests

The authors declare that they have no competing interests. 


\section{Availability of data and materials}

All data generated and analyzed during this study are included in this manuscript.

\section{Consent for publication}

All authors have approved to submit this work to Chemical and Biological Technologies in Agriculture. They declare that there is no conflict of interest in relation to the submission of the article.

\section{Ethics approval and consent to participate}

All authors approved to the ethics approval and all authors actively participated in the creation of this excellent work.

\section{Funding}

Not applicable.

\section{Publisher's Note}

Springer Nature remains neutral with regard to jurisdictional claims in published maps and institutional affiliations.

Received: 29 May 2017 Accepted: 3 October 2017

Published online: 07 November 2017

\section{References}

1. Qi H, Zhao T, Zhang Q, Li Z, Zhao Z, Xing R. Antioxidant activity of different molecular weight sulfated polysaccharides from Ulva pertusa Kjellm (Chlorophyta). J Appl Phycol. 2005;17:527-34

2. Van Oosten MJ, Pepe O, De Pascale S, Silletti S, Maggio A. The role of biostimulants and bioeffectors as alleviators of abiotic stress in crop plants. Chem Biol Technol Agric. 2017;4:5. doi:10.1186/ s40538-017-0089-5.

3. El Asri O, Ramdani M, Latrach L, Haloui B, Mohamed R, elamin Afilal M. Energetic valorization of Nador lagoon algae and proposal to use it as a means of elimination of the eutrophication in this lagoon. Ecol Eng. 2017;103:236-43. doi:10.1016/j.ecoleng.2017.04.016.

4. Yang Y-F, Fei X-G, Song J-M, Hu H-Y, Wang G-C, Chung IK. Growth of Gracilaria lemaneiformis under different cultivation conditions and its effects on nutrient removal in Chinese coastal waters. Aquaculture. 2006;254:248-55

5. Darcy-Vrillon B. Nutritional aspects of the developing use of marine macroalgae for the human food industry. Int J Food Sci Nutr (UK). 1993.

6. Ito K, Hori K. Seaweed: chemical composition and potential food uses. Food Rev. Int. 1989;5:101-44.

7. Lahaye M. Marine algae as sources of fibres: determination of soluble and insoluble dietary fibre contents in some "sea vegetables". J Sci Food Agric. 1991;54:587-94.

8. Liu M, Hansen PE, Lin X. Bromophenols in marine algae and their bioactivities. Mar Drugs. 2011;9:1273-92.

9. Peng J, Yuan J-P, Wu C-F, Wang J-H. Fucoxanthin, a marine carotenoid present in brown seaweeds and diatoms: metabolism and bioactivities relevant to human health. Mar Drugs. 2011:9:1806-28.

10. Sharma HSS, Selby C, Carmichael E, McRoberts C, Rao JR, Ambrosino P, Chiurazzi M, Pucci M, Martin T. Physicochemical analyses of plant biostimulant formulations and characterisation of commercial products by instrumental techniques. Chem Biol Technol Agric. 2016;3:13. doi:10.1186/s40538-016-0064-6.

11. Takamatsu S, Hodges TW, Rajbhandari I, Gerwick WH, Hamann MT, Nagle DG. Marine natural products as novel antioxidant prototypes. J Nat Prod. 2003;66:605-8.

12. Thomas NV, Kim S-K. Potential pharmacological applications of polyphenolic derivatives from marine brown algae. Environ Toxicol Pharmacol. 2011:32:325-35.

13. Zubia M, Fabre MS, Kerjean V, Le Lann K, Stiger-Pouvreau V, Fauchon M, Deslandes E. Antioxidant and antitumoural activities of some Phaeophyta from Brittany coasts. Food Chem. 2009;116:693-701.

14. Huang D, Ou B, Prior RL. The chemistry behind antioxidant capacity assays. J Agric Food Chem. 2005;53:1841-56.
15. Cohen K, Nyska A. Oxidation of biological system: oxidative stress phenomena, antioxidants, redox reactions and method for their quantification. Toxicol Path. 2002;30:620-50.

16. Yildiz G, Vatan Ö, Celikler S, Dere Ş. Determination of the phenolic compounds and antioxidative capacity in red algae Gracilaria bursa-pastoris. Int J Food Prop. 2011;14:496-502.

17. Safer AM, Al-Nughamish AJ. Hepatotoxicity induced by the anti-oxidant food additive, butylated hydroxytoluene (BHT), in rats: an electron microscopical study. Histol Histopathol. 1999;14(2):391-406.

18. Kabouche A, Kabouche Z, Öztürk M, Kolak U, Topçu G. Antioxidant abietane diterpenoids from Salvia barrelieri. Food Chem. 2007;102:1281-7.

19. El-Alami M, Mahjoubi R, Damnati B, Kamel S, Icole M, Taieb M. Sédimentologie et géochimie organique des sédiments superficiels de la lagune de Nador (Maroc nord-oriental). J Afr Earth Sci. 1998;26:249-59.

20. Erimesco P. La Mar Chica de Melilla. Bull Int Pêche Marit Maroc. $1961 ; 7: 3-11$.

21. Lapointe BE, Herren LW, Debortoli DD, Vogel MA. Evidence of sewagedriven eutrophication and harmful algal blooms in Florida's Indian River Lagoon. Harmful Algae. 2015;43:82-102.

22. De Almeida CL, Falcão DS, Lima DM, Gedson R, Montenegro DA, Lira NS, De Athayde-Filho PF, Rodrigues LC, De Souza MD, Barbosa-Filho JM, Batista LM. Bioactivities from marine algae of the genus Gracilaria. Int J Mol Sci. 2011;12(7):4550-73.

23. Anggadiredja J, Andyani R. Antioxidant activity of Sargassum polycystum (Phaeophyta) and Laurencia obtusa (Rhodophyta) from Seribu islands. J Appl Phycol. 1997;9:477-9.

24. Fallarero A, Loikkanen JJ, Männistö PT, Castañeda O, Vidal A. Effects of aqueous extracts of Halimeda incrassata (Ellis) Lamouroux and Bryothamnion triquetrum (SG Gmelim) Howe on hydrogen peroxide and methyl mercury-induced oxidative stress in GT1-7 mouse hypothalamic immortalized cells. Phytomedicine. 2003;10:39-47.

25. Lim SN, Cheung PCK, Ooi VEC, Ang PO. Evaluation of antioxidative activity of extracts from a brown seaweed, Sargassum siliquastrum. J Agric Food Chem. 2002;50:3862-6.

26. Santoso J, YOSHIE-STARKY, Suzuki T. Anti-oxidant activity of methanol extracts from Indonesian seaweeds in an oil emulsion model. Fish Sci. 2004:70(1):183-8.

27. Singleton VL, Orthofer R, Lamuela-Raventós RM. [14] Analysis of total phenols and other oxidation substrates and antioxidants by means of folin-ciocalteu reagent. Methods Enzymol. 1999;299:152-78.

28. Lamaison JL, Carnart A. Teneurs en principaux falvonoïdes des fleurs et des feuilles de Crataegus monogyna Jacq. et de Crataegus laevigata (Poiret) DC. en fonction de la période de végétation. Plantes Médicinales Phythér. 1991;25:12-6.

29. Alimi H, Hfaiedh N, Bouoni Z, Sakly M, Ben Rhouma K. Evaluation of antioxidant and antiulcerogenic activities of Opuntia ficus indica F. inermis flowers extract in rats. Environ Toxicol Pharmacol. 2011;32:406-16. doi:10.1016/j.etap.2011.08.007.

30. Blois MS. Antioxidant determinations by the use of a stable free radical. Nature. 1958;181:1199-200. doi:10.1038/1811199a0.

31. Behrendorff JB, Vickers CE, Chrysanthopoulos P, Nielsen LK. 2,2-Diphenyl1-picrylhydrazyl as a screening tool for recombinant monoterpene biosynthesis. Microb Cell Factories. 2013;12:76. doi:10.1186/1475-2859-12-76.

32. Hernandez Y, Lobo M, Gonzalez M. Factors affecting sample extraction in the liquid chromatographic determination of organic acids in papaya and pineapple. Food Chem. 2009;114:734-41. doi:10.1016/j. foodchem.2008.10.021

33. Azmir J, Zaidul ISM, Rahman MM, Sharif KM, Mohamed A, Sahena F, Jahurul MHA, Ghafoor K, Norulaini NAN, Omar AKM. Techniques for extraction of bioactive compounds from plant materials: a review. J Food Eng. 2013;117:426-36. doi:10.1016/j.jfoodeng.2013.01.014.

34. Bravo L. Polyphenols: chemistry, dietary sources, metabolism, and nutri tional significance. Nutr Rev. 1998:56:317-33.

35. Ramdani M, Sahnouni F, Haloui B, Roger NE, Mesfioui FA, Ramdani M. Macroepiphytes and macroalgae (Phaeophyceae, rhodophyceae and chlorophyceae) in the nador lagoon (Morocco). J Biodivers Env Sci. 2015:7:252-61.

36. Horincar V-B, Parfene P, Bahrim G. Evaluation of bioactive compounds in extracts obtained from three Romanian marine algae species. Romanian Biotechnol Lett. 2011;16:71-8. 
37. Jiménez-Escrig A, Jiménez-Jiménez I, Pulido R, Saura-Calixto F. Antioxidant activity of fresh and processed edible seaweeds. J Sci Food Agric. 2001;81:530-4.

38. Karawita R, Siriwardhana N, Lee K-W, Heo M-S, Yeo I-K, Lee Y-D, Jeon Y-J. Reactive oxygen species scavenging, metal chelation, reducing power and lipid peroxidation inhibition properties of different solvent fractions from Hizikia fusiformis. Eur Food Res Technol. 2005;220:363-71.

39. Manian R, Anusuya N, Siddhuraju P, Manian S. The antioxidant activity and free radical scavenging potential of two different solvent extracts of Camellia sinensis (L.) O. Kuntz, Ficus bengalensis L. and Ficus racemosa L. Food Chem. 2008;107:1000-7.
40. Siriwardhana N, Lee K-W, Jeon Y-J, Kim S-H, Haw J-W. Antioxidant activity of Hizikia fusiformis on reactive oxygen species scavenging and lipid peroxidation inhibition. Food Sci Technol Int. 2003;9:339-46.

41. Velioglu YS, Mazza G, Gao L, Oomah BD. Antioxidant activity and total phenolics in selected fruits, vegetables, and grain products. J Agric Food Chem. 1998;46:4113-7. 